\title{
The Benefits of Delayed Primary School Enrollment Discontinuity Estimates Using Exact Birth Dates
}

\author{
Patrick J. McEwan \\ Joseph S. Shapiro
}

\begin{abstract}
A B S T R A C T
The paper estimates the effect of delayed school enrollment on student outcomes, using administrative data on Chilean students that include exact birth dates. Regression-discontinuity estimates, based on enrollment cutoffs, show that a one-year delay decreases the probability of repeating first grade by two percentage points, and increases fourth and eighth grade test scores by more than 0.3 standard deviations, with larger effects for boys. The paper concludes with implications for enrollment age policy.
\end{abstract}

\section{Introduction}

All countries specify an appropriate age for primary school enrollment (UNESCO 2007). Many countries further enforce a minimum age by requiring that students' birthdays precede an enrollment cutoff (for example, to enroll in kindergarten students must turn five years old by the second month of the school year). ${ }^{1}$

1. On the use of cutoff dates in the United States and OECD countries, respectively, see Elder and Lubotsky (2006) and Bedard and Dhuey (2006). McEwan (2006) identifies Latin American countries, including Chile, that apply cutoff dates.

Patrick J. McEwan is an associate professor of economics at Wellesley College. Joseph S. Shapiro is a graduate student in the Department of Economics at MIT. The authors thank Amanda Brewster, Deon Filmer, Jeff Marshall, Emiliana Vegas, Gaston Yalonetzky, two anonymous referees, and seminar participants at the World Bank, Washington University, Michigan State, and Stanford for providing helpful comments. This research received partial financial support from the World Bank. The views expressed herein are those of the authors. The SIMCE and JUNAEB data are available with the permission of Chile's Ministry of Education and JUNAEB, respectively. Conditional on receiving permission, the data set used in the article can be obtained beginning August 2008 through July 2011 from Patrick McEwan, Wellesley College, pmcewan@wellesley.edu. The TIMSS data are publicly available.

[Submitted July 2006; accepted March 2007]

ISSN 022-166X E-ISSN 1548-8004 (C) 2008 by the Board of Regents of the University of Wisconsin System

THE JOURNAL OF HUMAN RESOURCES • XLIII • I 
Over the past 30 years, changes in state-specific laws have moved cutoffs earlier in school years and increased kindergarten entrance ages in the United States (Elder and Lubotsky 2006; Stipek 2002). Regardless of the specified enrollment age, some parents - up to a tenth in the United States_-voluntarily delay their children's primary school enrollment (McEwan 2006; Stipek 2002).

A growing body of empirical research documents costs and benefits to such delays. Costs include childcare for unenrolled children, ${ }^{2}$ shorter work careers for older graduates, and less formal schooling. Empirical research in the United States, for example, shows that individuals born after enrollment cutoffs-who are obliged to enroll in school at older ages-acquire less schooling on average (Angrist and Krueger 1991; Cascio and Lewis 2006; McCrary and Royer 2006). ${ }^{3}$

In the absence of substantial benefits, it is difficult to explain why parents choose to delay enrollment (Glewwe and Jacoby 1995). Some psychologists argue that older children acquire greater "readiness" for learning, and can acquire skills more quickly (Stipek 2002). If these skills produce large and sustained economic returns, then governments and parents may find it advantageous to delay enrollment. An empirical literature, to which our paper contributes, tests these assertions by estimating and interpreting the causal effect of enrollment age on a range of school outcomes, especially test scores.

As empirical leverage, the literature exploits the fact that a subset of children begin school at an older age simply because they are born after an enrollment cutoff date (Bedard and Dhuey 2006; Datar 2006; Elder and Lubotsky 2006; Fredriksson and Öckert 2005). Empirical estimates relying on nominally exogenous variation suggest that - in the United States and OECD countries-a one-year increase in enrollment age causes large declines in the probability of grade retention, ${ }^{4}$ modest increases in test scores until at least the eighth grade, ${ }^{5}$ and, in a few contexts, increases in higher education participation (Bedard and Dhuey 2006).

This paper makes three contributions to this literature, using a related empirical strategy. First, it employs unusually good data from Chile, including administrative surveys of first graders from several years and linked administrative test score data for a subset of fourth graders. The data also include a representative sample of eighth

2. School attendance provides an implicit childcare subsidy to parents that is forgone by the decision to delay a child's enrollment. Consistent with this notion, empirical research finds that maternal employment is responsive to kindergarten access (Berlinski and Galiani 2007; Cascio 2006; Gelbach 2002).

3. The effects are plausibly explained by rules that compel attendance until a specified age, when laterenrolling students are permitted to drop out having completed fewer grades. However, the attainment effects could persist even if schooling is compulsory until students complete a specified grade (McCrary and Royer 2006). In developing countries, a likely source of lower attainment among later-enrolling children is a higher opportunity cost of time among older children, and the incentive to withdraw such children from school (Urquiola and Calderón 2006).

4. Elder and Lubotsky (2006) estimate reductions in the probability of early- and later-grade retention of 0.13 and 0.15 , respectively.

5. Elder and Lubotsky (2006) estimate test score effects of 0.5 to 0.8 standard deviations at the beginning of kindergarten, and 0.1 and 0.2 in a different data set of eighth graders. Datar (2006) estimates similar differences at the beginning of kindergarten, but also finds effects of 0.07 to 0.1 standard deviations on test score gains in the first two years of school. Bedard and Dhuey (2006) find effects in OECD countries of 0.12 to 0.35 standard deviations on fourth grade scores and slightly smaller effect of 0.08 to 0.26 on eighth grade score. In Swedish data, Fredriksson and Öckert (2005) find effects on school performance of 0.2 standard deviations. 
graders, drawn from the 1999 Trends in Mathematics and Science Study (TIMSS). Each data set records each student's exact date of birth which, in concert with large samples, facilitates precise regression-discontinuity estimates of enrollment age effects, driven by students born close to the enrollment cutoff. (In most Chilean schools, which start classes in early March, first graders must turn six years old before July 1.) The estimates suggest that, among students induced to delay enrollment by cutoff rules, a one-year delay decreases a student's probability of being retained in the first grade by two percentage points (given a sample mean of 2.8 percent), and increases test scores by 0.3 to 0.4 standard deviations in the fourth grade, with similar or perhaps larger effects in the eighth grade.

Second, the paper carefully tests the identifying assumption that day of birth is random near enrollment cutoffs. ${ }^{6}$ The concern is that motivated parents "game" enrollment cutoffs by scheduling births on either side, inducing spurious differences in student outcomes close to cutoffs. ${ }^{7}$ Prior research cannot fully test for gaming because of smaller samples, coarse birth date measures, or both (for an exception, see McCrary and Royer 2006). The concern may seem far-fetched, but U.S. parents schedule births in order to avoid taxes (Dickert-Conlin and Chandra 1999). Forty percent of Chileans are born via cesarean section-perhaps the highest rate of any country (Belizán et al. 1999; Murray 2000)_giving us ample reason to presume that scheduled births could invalidate the identifying assumption. ${ }^{8}$ We find scant evidence that birth frequencies or observed socioeconomic characteristics of students vary sharply around enrollment cutoffs, providing confidence that unobserved variables also vary smoothly around these cutoffs.

Third, our results provide evidence on the mechanisms by which enrollment age affects outcomes. In most data, including ours, students who delay enrollment are older when they take tests. Thus, typical estimates of enrollment age effects capture both an "age-at-test" effect and a true "enrollment age" effect (Datar 2006; Elder and Lubotsky 2006). The former effect plausibly dissipates over time, since a year of maturation represents more learning among young children than among adolescents or adults. The latter effect is of greatest interest to school systems and parents, since it could represent a persistent advantage for children enrolling at older ages. Our results suggest that test score effects are at least stable and probably growing over time, providing a prima facie case that age-at-test cannot fully explain the results.

The paper proceeds as follows. Section II describes the empirical strategy and its pitfalls, while Section III describes the data. Sections IV and V discuss results for first grade retention and test score outcomes, respectively. Section VI discusses mechanisms that could explain the pattern of results, while Section VII concludes with implications for policy toward enrollment ages.

6. A related concern is seasonality of conception (Bound, Jaeger, and Baker 1995; Bound and Jaeger 2000), which could produce correlations between month or season of birth and unobserved student or family variables that affect student outcomes. In the present study, we address this concern by controlling for polynomials of exact birth date.

7. Precise birth timing is a specific instance of assignment variable manipulation in the regression discontinuity design (Lee, Forthcoming; McCrary, Forthcoming).

8. Some argue that high rates are due to incentives created by private health insurance reforms (Murray 2000), though neighboring countries have similarly high rates (Belizán et al. 1999). 


\section{Empirical Strategy}

\section{A. Identification and Estimation}

We use data on Chilean students to estimate the causal effect of enrollment age on student outcomes. A linear model estimated by OLS provides a starting point:

$$
O_{i g}=\beta_{0}+\beta_{1} A_{i}+X_{i} \beta_{2}+\varepsilon_{i g}
$$

where $O_{i g}$ is the outcome of student $i$ at the end of grade $g, A_{i}$ is the student's age in decimal years upon beginning the first grade, $X_{i}$ is a vector of child and family variables determined before the child's birth, and the independent errors $\varepsilon_{i g}$ are distributed $N\left(0, \sigma^{2}\right) . \beta_{1}$ represents the effect of delaying enrollment by one year. If $\operatorname{Cov}\left(A_{i}, \varepsilon_{i g}\right) \neq 0$, then $\hat{\beta}_{1}^{O L S} \neq \beta_{1}$. This seems possible, since children with lower (and unobserved) physical, cognitive, or social readiness-all potentially correlated with outcomes - are more likely to delay enrollment.

To improve on Equation 1, we exploit exogenous variation in the first grade enrollment age created by Chile's enrollment cutoff dates, since students turning six on or after cutoff dates must delay enrollment by one year. Chile's official enrollment cutoff is April 1, and its school year begins on March 1, implying a minimum enrollment age of 5.92 years. In practice, a Ministry of Education decree allows schools to implement cutoff dates as late as July 1, and correspondingly lower minimum enrollment ages (República de Chile 1992). We present empirical evidence that sharp cutoffs appear on the first day of April, May, June, and July, though the last is the most common in Chilean schools.

Identification of enrollment age effects is based on comparing the outcomes of "treated" students' outcomes, born on or just to the right of cutoffs, with those of untreated students born just to the left of cutoffs. The causal interpretation of such comparisons hinges upon the assumption that birth dates are random near cutoffs, akin to a very local randomized experiment (Lee, Forthcoming). At the very least, we must assume that precise birth timing near cutoffs does not introduce sharp differences in unobserved variables that affect student outcomes.

To obtain estimates based on this variation, let $B$ denote a student's day of birth in the calendar year, omitting the $i$ subscript. Allowing for leap years, $B=1$ for birthdays falling on January 1 and $B=366$ for birthdays falling on December 31 . Define four dummy variables, $D_{j}=1\left(B \geq \bar{B}_{j}\right) \forall j \in\{1,2,3,4\}$, indicating values of $B$ that equal or exceed enrollment cutoffs. ${ }^{9}$ To compare student outcomes around each discontinuity, we estimate the following equation via OLS:

$$
O=\phi_{0}+\phi_{1} D_{1}+\phi_{2} D_{2}+\phi_{3} D_{3}+\phi_{4} D_{4}+f(B)+u
$$

where $f(B)$ is a function of $B$ that captures smooth, seasonal effects of birth dates on student outcomes. ${ }^{10}$ We specify it as a piecewise quadratic polynomial (though later we visually assess the fit of this functional form, and also use a higher-order polynomial):

9. The enrollment cutoffs are $\bar{B}_{1}=92$ (April 1), $\bar{B}_{2}=122$ (May 1), $\bar{B}_{3}=153$ (June 1), and $\bar{B}_{4}=183$ (July 1).

10. For related specifications and discussion, see McCrary and Royer (2006) and van der Klaauw (2002). 
(3) $f(B)=\sum_{k=1}^{2} \delta^{k} B^{k}+\sum_{j=1}^{4} \sum_{k=1}^{2} \delta_{j}^{k} D_{j}\left(B-\bar{B}_{j}\right)^{k}$

where $\delta_{j}$ represent coefficients on polynomial terms.

In Equation 2, the $\phi_{j}$ terms summarize the sharp differences in outcomes between students born close to each enrollment cutoff, due to the enrollment delay treatment. However, three possible behaviors of parents suggest that such estimates only capture intent-to-treat effects for such students. First, parents can voluntarily delay a child's enrollment beyond the legal minimum age. Second, parents can demand that local school personnel allow the child to enroll before the child reaches the legal minimum age. Third, families can choose between schools that apply different enrollment cutoff dates. ${ }^{11}$

Given the possibility of these behaviors, we estimate the following equations via two-stage least squares (TSLS):

$A=\alpha_{0}+\alpha_{1} D_{1}+\alpha_{2} D_{2}+\alpha_{3} D_{3}+\alpha_{4} D_{4}+f(B)+v$

$$
O=\beta_{0}+\beta_{1} A+f(B)+\varepsilon
$$

Estimates of Equation 4 reveal whether birthdays near enrollment cutoffs create sharp variation in enrollment age. Given partial compliance and the four discontinuities, we anticipate that $\alpha_{j}<1 \forall j \in\{1,2,3,4\}$. In Equation 5, $\beta_{1}$ is the causal effect on $O$ of a one-year increase in enrollment age. If treatment effects vary across students, $\beta_{1}$ is the weighted average of four local average treatment effects (LATES), with weights proportional to the ability of each $D$ instrument to predict enrollment age (Angrist and Imbens 1995). We also can generate four estimates of the causal effect at each cutoff $\overline{\mathrm{B}}_{j} .{ }^{12}$ We interpret the four estimates as LATEs for students with birthdays near the respective cutoffs who are induced to delay enrollment.

\section{B. Threats to Internal Validity}

For Equations 4 and 5 to provide a consistent estimator of $\beta_{1}$, the excluded instruments must be uncorrelated with unobserved variables that influence outcomes:

$$
\operatorname{cov}\left(D_{j}, \varepsilon\right)=0 \quad \forall j \in\{1,2,3,4\}
$$

A first concern is that precise choice of births, among families with unobserved attributes that affect outcomes, could introduce correlation between $D_{j}$ and the error $\varepsilon$. The most likely possibility is that higher-income parents, with greater access to medical services, schedule births to fall on one side of the cutoff or another. A second concern is that administrative data (but not the separate TIMSS sample) exclude a portion of students who attend private schools. (The next section discusses this

11. Chile's ample school choice (McEwan and Carnoy 2000; Hsieh and Urquiola 2006) makes this feasible.

12. We estimate the first-stage Equation 4, and then four variants of Equation 5, each controlling for three of four $D_{j}$. For example, a second-stage regression controlling for $D_{1}$ to $D_{3}$ would identify an effect in the vicinity of the July 1 cutoff (also see van der Klaauw 2002). 
issue in more detail.) If a child's probability of attending such schools changes sharply at an enrollment cutoff, sample selection also could invalidate Assumption $6 .^{13}$

To see whether precise sorting and sample selection affect our estimates, we implement two tests of necessary conditions for Equation 6. First, we iterate estimation of Equation 2 using the $X$ as dependent variables. In each iteration, we test the null hypotheses $\phi_{j}=0 \forall j \in\{1,2,3,4\}$. Failure to reject these hypotheses implies that observed covariates vary smoothly around enrollment cutoffs. Second, we examine whether including predetermined $X$ in Equations 4 and 5 changes $\hat{\beta}_{1}^{T S L S}$. If Assumption 6 is true, then including predetermined variables will not change the magnitude of $\hat{\beta}_{1}^{T S L S}$.

We also use three strategies that provide suggestive evidence for Assumption 6 but do not provide necessary or sufficient conditions for it. First, we examine histograms for unusual breaks around the enrollment cutoffs, since such breaks suggest that birth timing may invalidate Assumption 6. Second, we report estimates for Chilean regions with better sample coverage of first grade students. If sample selection does not affect results and if treatment effects are homogenous across regions, we will obtain similar estimates for $\beta_{1}$ with the entire data set and with the subsample. Third, we corroborate findings from the administrative data with a separate sample of Chilean eighth graders - the Trends in Mathematics and Science Study (TIMSS) sample - that is not subject to sample selection.

\section{Data}

\section{A. First Grade JUNAEB Data}

We use eight annual surveys (1997-2004) of first graders, collected by the National School Assistance and Scholarship Board (JUNAEB), the government agency responsible for a school meals program. In the first two months of each school year, the agency surveys every first grader in all public and the majority of private schools. First grade teachers report a student's exact birth date, weight, height, gender, years of mothers' schooling, and a unique identification number similar to a U.S. Social Security number.

We construct variables that measure students' first grade retention (a binary outcome, $O),{ }^{14}$ exact enrollment age $(A)$, and background variables $(X)$. We assume that students are retained in the first grade if they appear in a subsequent first grade

13. Suppose that high-income parents of children born on April 1 dislike the April 1 cutoff of their local public school and instead enroll their child in a tuition-charging private school which does not appear in our data, and which uses a July 1 cutoff. This might introduce illusory change in student outcomes close to the April 1 discontinuity. One option is to test whether the probability of appearing in the data changes discontinuously at enrollment cutoffs (Lemieux and Milligan 2005; McCrary and Royer 2006), but since Chile does not process daily natality records for all children, we cannot obtain data on the birth dates of children excluded from the sample, and cannot implement such a test.

14. We interpret first grade retention as an indicator of low, unobserved achievement upon completing the school year. Since retained students must complete a second year, it is also a helpful indicator of costs to taxpayers (additional school resources) and individuals (stigma and opportunity cost of time). 
survey, based upon their identification number. The measure has the advantage of identifying grade retention even when students switch schools. In the same manner, we define a student's exact enrollment age $(A)$ as the days elapsed between birth and March 1 of the first survey round in which the student appears in the data, divided by 365.25. We extract four student characteristics $(X)$, described in Table 1, including gender, years of mother's schooling, ${ }^{15}$ and two anthropometric measures of nutritional status.

To arrive at a working sample, we apply several exclusions to these data (for details and sample sizes, see McEwan and Shapiro 2006). First, we exclude the first (1997) and last (2004) rounds of the survey. In the first year, we cannot impute students' first grade enrollment age, since students could have appeared in an earlier, unobserved round of the survey. In the last year, we cannot impute grade retention, since students might appear in a later, unobserved round. Second, we exclude all students attending rural schools. In small, rural schools, it appears that "first grade" surveys were expanded to include students in upper primary grades in order to increase sample size, though actual grade is not recorded in all survey years. Third, we include the first observation of each student in the first grade, and drop subsequent observations if the student is retained. Fourth, we drop the few observations that are missing values of the dependent or independent variables.

The final JUNAEB sample includes just over one million observations in 3,274 urban schools (Table 1). The full sample contains 71 percent of urban schools and 75 percent of urban first graders in the 1998 to 2003 school years. ${ }^{16}$ The diminished coverage is mainly due to the fact that the JUNAEB survey does not survey the entire population of schools in any year. It excludes all private schools that charge tuition, and a portion of private schools that receive government subsidies (on school types in Chile, see McEwan and Carnoy 2000).

\section{B. Fourth Grade SIMCE Data}

We augment first grade JUNAEB data with a census of fourth grade students, collected in November 2002 by the National System of Education Quality Measurement (SIMCE), a unit of the Ministry of Education. As outcome variables, we extract item response theory test scores in mathematics and Spanish, and use their Z-scores. We also extract students' identification numbers-available in a restricted-use version of the data set-for matching a student's SIMCE test scores with the same student's observation in the JUNAEB sample. The final SIMCE sample includes 144,047 observations on fourth graders in 2002. As expected, the 1999 first grade JUNAEB survey provides the match for 92 percent of the final SIMCE sample (Table 1). The 1998 first grade JUNAEB survey provides the match for the smaller number of SIMCE fourth graders who were retained in an earlier grade. ${ }^{17}$

15. Survey years vary in how they record postsecondary schooling, so a value of 13 indicates at least some postsecondary schooling. When estimating variants of Equations 2, 4, and 5, we include a series of categorical dummy variables.

16. We calculated sample coverage using supplementary administrative enrollment data, described in McEwan and Shapiro (2006).

17. Fourth graders in 2002 are not matched if they were retained more than once, but the number of such students in the Chilean data is less than 3 percent (McEwan and Shapiro 2006). 


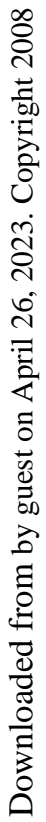

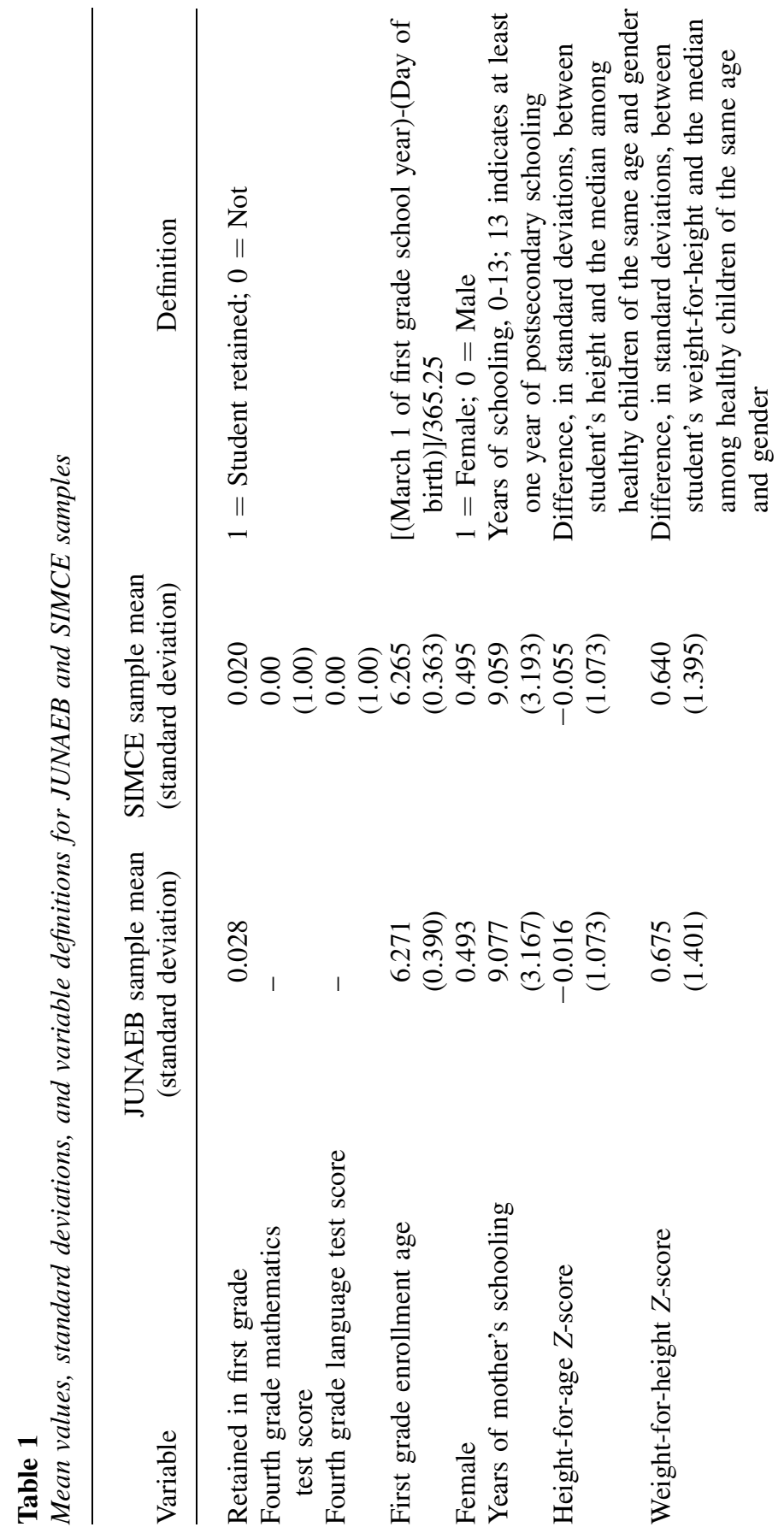




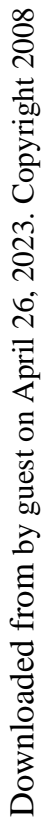

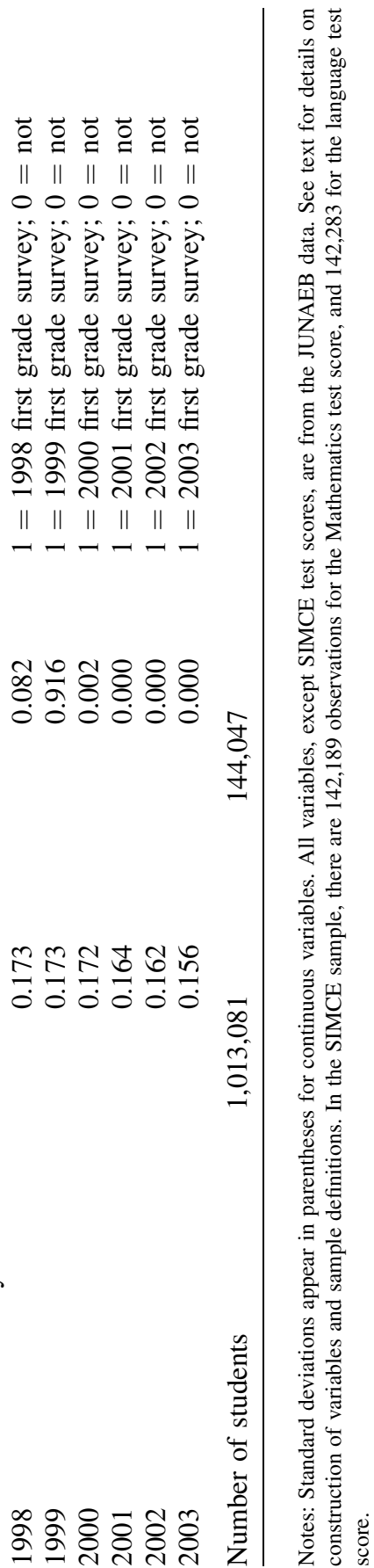




\section{Eighth Grade TIMSS Data}

We use an international assessment of eighth grade students, collected under the auspices of the 1999 Trends in Mathematics and Science Study (TIMSS). In November 1998, the Chilean Ministry of Education applied TIMSS math and science tests to a nationally representative sample of 5,907 eighth graders in 185 schools. It is the only data set collected in an upper primary grade that reports exact birth date. The 2002 Chilean application of TIMSS, for example, does not. We extract the Rasch item response theory scores for mathematics and science, and use their Z-scores. ${ }^{18}$ Using students' birth dates, we calculate eighth graders' exact age at the beginning of the 1998 school year. As student controls, we use each student's gender, categorical measures of mother's and father's schooling, a categorical measure of books in the home, an asset index, household residency variables, and the school's rural or urban location. ${ }^{19} \mathrm{We}$ exclude students with missing birth dates, leading to a final TIMSS sample of $5,582 .^{20}$

\section{Descriptive Statistics}

In the JUNAEB sample, the average student entered first grade at age 6.3, and 2.8 percent of students are retained in the first grade (Table 1). The latest possible enrollment cutoff is July 1, implying a minimum enrollment age of 5.67. Less than 1 percent of the sample violates this cutoff by enrolling earlier (Table 2). Some schools use cutoffs as early as April 1, implying a minimum enrollment age of 5.92 years and a maximum of 6.92. Table 2, Panel A shows that only 2.6 percent of students delay enrollment past 6.92 years of age.

Students who voluntarily delay enrollment past 6.92 years have greater probabilities of being retained in the first grade and much lower test scores (Table 2). The same children that delay enrollment also have less-educated mothers, worse anthropometric indicators, and are more likely to be male. They also, presumably, differ on unobservable dimensions that affect outcomes, thus biasing enrollment age effects based on Equation 1.

\section{Effects on First Grade Retention}

\section{A. Results}

The top panel of Figure 1 graphs first grade enrollment age against day of birth. The points show means within day-of-birth cells, and they reveal sharp increases in

\footnotetext{
18. The adjustment models the probability a respondent will correctly answer a test score item as a function of the student's latent ability and the item's difficulty. This scaling sharpens the correspondence between a one-point test score increase and a one-unit increase in a student's cognitive skills (Yamamoto and Kulick 1999).

19. We calculate the asset index from factor analysis, using indicators of items in the student's home (see McEwan and Shapiro 2006 for details). Home residency variables include indicators for whether the student lives with the student's mother, father, brother(s), sister(s), stepmother, stepfather, and grandparent(s). 20. Students did not report values for all variables. In regression analyses, we replace missing values with zero and include additional dummy variables indicating missing values.
} 


\section{Table 2}

Variable means, by enrollment age

\begin{tabular}{|c|c|c|c|c|}
\hline & \multicolumn{4}{|c|}{ First grade enrollment age category } \\
\hline & $\begin{array}{l}<5.67 \\
\text { years }\end{array}$ & $\begin{array}{l}\geq 5.67 \text { and } \\
<6.67 \text { years }\end{array}$ & $\begin{array}{l}\geq 6.67 \text { and } \\
<6.92 \text { years }\end{array}$ & $\begin{array}{r}\geq 6.92 \\
\text { years }\end{array}$ \\
\hline \multicolumn{5}{|l|}{ Panel A: JUNAEB sample } \\
\hline Retained in first grade & $0.045^{* *}$ & 0.027 & 0.026 & $0.060 * *$ \\
\hline $\begin{array}{l}\text { Years of mother's } \\
\text { schooling }\end{array}$ & 8.970 & 9.138 & $8.887 * *$ & $7.466 * *$ \\
\hline Female student & 0.489 & 0.496 & $0.470 * *$ & $0.449 * *$ \\
\hline Height-for-age $Z$-score & 0.007 & -0.014 & $-0.029 * *$ & $-0.061 * *$ \\
\hline $\begin{array}{l}\text { Weight-for-height } \\
\text { Z-score }\end{array}$ & 0.669 & 0.676 & $0.658 * *$ & $0.659 *$ \\
\hline Observations & 6,844 & 910,085 & 70,354 & 25,798 \\
\hline $\begin{array}{c}\text { Percent of total } \\
\text { observations }\end{array}$ & $0.7 \%$ & $89.8 \%$ & $6.9 \%$ & $2.6 \%$ \\
\hline \multicolumn{5}{|l|}{ Panel B: SIMCE sample } \\
\hline $\begin{array}{l}\text { Fourth grade math } \\
\text { test score }\end{array}$ & -0.061 & 0.007 & 0.022 & $-0.360 * *$ \\
\hline Observations & 1,025 & 127,832 & 10,256 & 3,076 \\
\hline $\begin{array}{c}\text { Percent of total } \\
\text { observations }\end{array}$ & $0.7 \%$ & $89.9 \%$ & $7.2 \%$ & $2.2 \%$ \\
\hline $\begin{array}{l}\text { Fourth grade language } \\
\text { test score }\end{array}$ & -0.024 & 0.005 & $0.043^{* *}$ & $-0.330 * *$ \\
\hline Observations & 1,022 & 127,918 & 10,255 & 3,088 \\
\hline $\begin{array}{c}\text { Percent of total } \\
\text { observations }\end{array}$ & $0.7 \%$ & $89.9 \%$ & $7.2 \%$ & $2.2 \%$ \\
\hline
\end{tabular}

Notes: Each row reports variable means by four enrollment age categories. $* *(*)$ indicates that a row mean is statistically different from the mean of students in the second category (enrollment at $\geq 5.67$ and $<6.67$ years) at 1 percent ( 5 percent). Hypothesis tests account for clustering of students within schools.

enrollment age on the first days of April, May, June, and July. The first three cutoffs show differences of less than 0.1 years, and July 1 indicates a difference of half a year. The solid line plots fitted values from the piecewise quadratic spline in Equation 3. The bottom panel of Figure 1 examines whether sharp variation in enrollment age near the cutoffs is accompanied by changes in first grade retention (as in the reduced form in Equation 2). Students born on July 1 and thereafter have a lower probability of retention, by approximately one percentage point-a substantial effect given the full sample mean retention rate of 2.8 percent. 

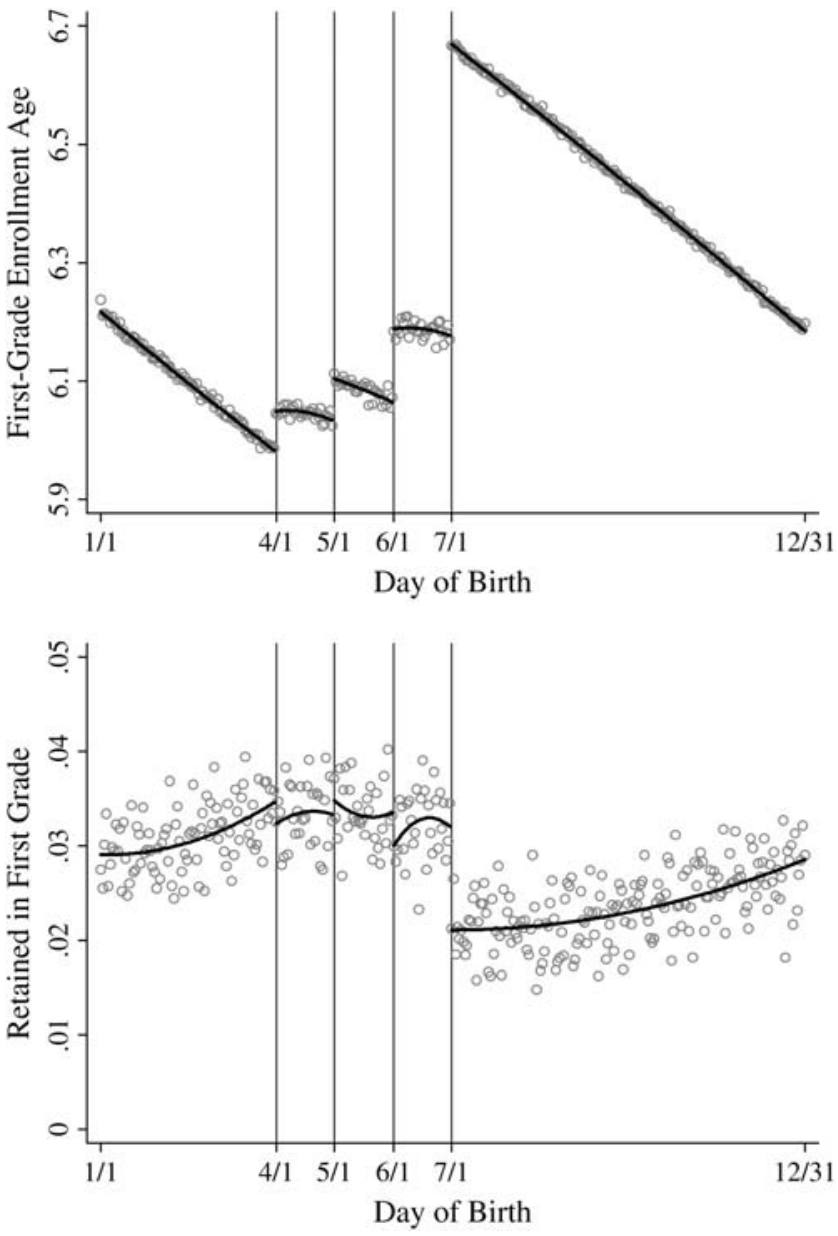

\section{Figure 1}

Day of Birth, First grade Enrollment Age, and First grade Retention Source: JUNAEB sample.

Note: The dots are mean values of the $y$-axis variable within each day of birth. The solid lines are fitted values from a piecewise quadratic of day of birth (see text for details).

Tables 3 and 4 summarize estimates from first-stage, reduced-form, and TSLS regressions that mirror Figure $1 .^{21}$ The first-stage estimates (Table 3, Columns 1 to 3) confirm that enrollment age increases around enrollment cutoffs, particularly July 1.

21. Regression estimates adjust standard errors for clustering within 366 day-of-birth cells (Lee and Card, Forthcoming). 


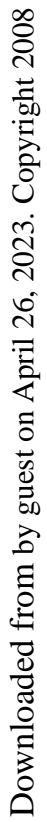

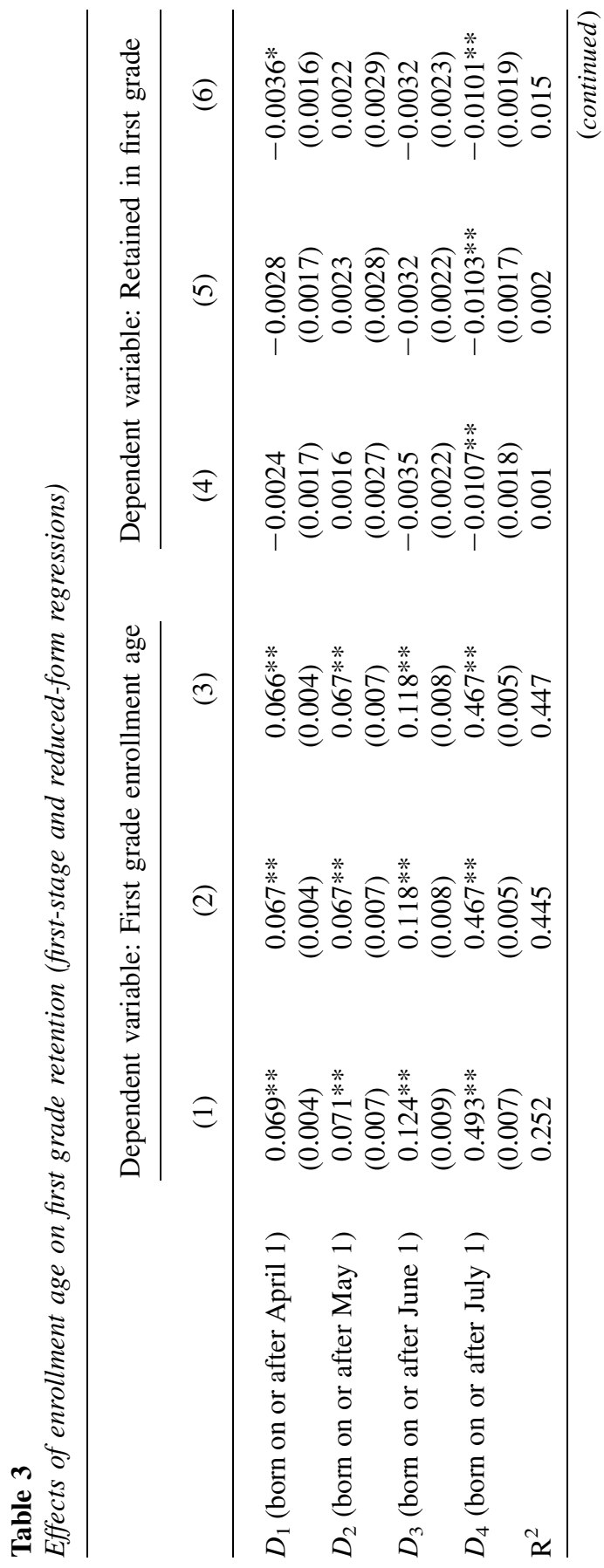




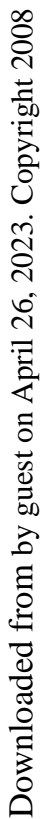

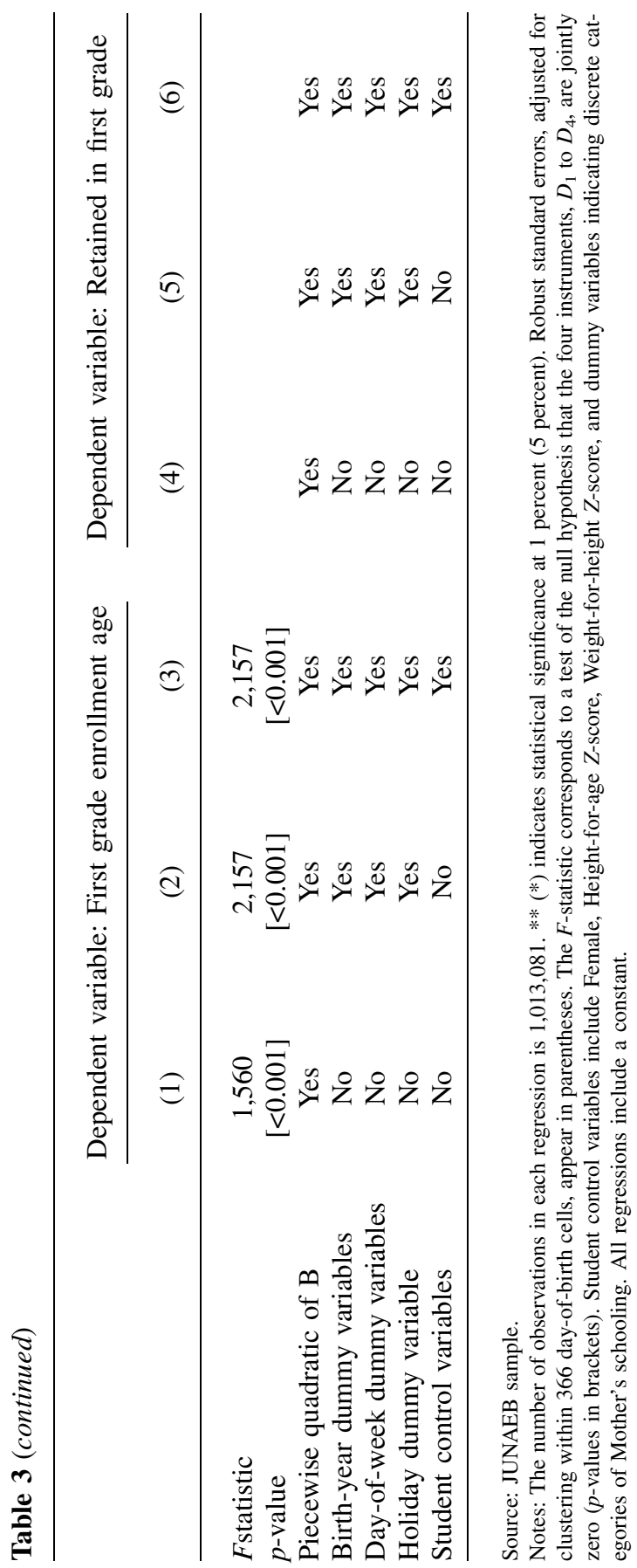




\section{Table 4}

Effects of enrollment age on first grade retention (TSLS regressions)

Dependent variable: Retained in the first grade

\begin{tabular}{llll}
\hline OLS & TSLS & TSLS & TSLS \\
\hline
\end{tabular}

(1)

(2)

(3)

Panel A: Excluded instruments: $D_{1}, D_{2}, D_{3}$, and $D_{4}$

First grade enrollment age $-0.0062^{* *}-0.0216^{* *}-0.0216^{* *}-0.0214 * *$
$\chi^{2}$ (Hansen $\mathrm{J}$ test)
(0.0007)
(0.0033)
(0.0035)
(0.0037)
$p$-value
$\chi^{2}$ (Durbin-Wu-Hausman test)
1.511
2.173
2.750
[0.680]
[0.537]
[0.432]
$p$-value
13.922
12.076
10.972
[0.000]
[0.001]
[0.001]

Panel B: Excluded instrument: $D_{1}$ (born on or after April 1)
First grade enrollment age
-0.0345
$(0.0245)$
$\begin{array}{cr}-0.0412 & -0.0540 * \\ (0.0247) & (0.0229)\end{array}$

Panel C: Excluded instrument: $D_{2}$ (born on or after May 1)
First grade enrollment age

$$
\begin{aligned}
& 0.0220 \\
& (0.0362)
\end{aligned}
$$
0.0346
0.0327
(0.0407)
$(0.0422)$

Panel D: Excluded instrument: $D_{3}$ (born on or after June 1)

$$
\begin{array}{llcc}
\text { First grade enrollment age } \quad-\quad & -0.0284 & -0.0271 & -0.0268 \\
& (0.0191) & (0.0197) & (0.0198)
\end{array}
$$

Panel E: Excluded instrument: $D_{4}$ (born on or after July 1)

First grade enrollment age

Piecewise quadratic of B

Birth-year dummy variables

Day-of-week dummy variables

Holiday dummy variable

Student control variables

$$
-0.0218 * *
$$$$
\text { (0.0035) }
$$

$$
-0.0216^{* *}
$$

(0.0039)

$\begin{array}{ll}\text { No } & \text { Yes } \\ \text { Yes } & \text { No } \\ \text { No } & \text { No } \\ \text { No } & \text { No } \\ \text { Yes } & \text { No }\end{array}$

Yes

Yes

Yes

Yes

Yes

Source: JUNAEB sample.

Notes: The number of observations in each regression is $1,013,081$. ** (*) indicates statistical significance at 1 percent ( 5 percent). Robust standard errors, adjusted for clustering within 366 day-of-birth cells, are in parentheses. Cells in Columns 2, 3, and 4 report the coefficient on First grade enrollment age from separate TSLS regressions that use different excluded instruments (see panel headings) and controls (see bottom of table). Student control variables include Female, Height-for-age $Z$-score, Weight-for-height $Z$-score, and dummy variables indicating discrete categories of Mother's schooling. All regressions include a constant.

Each instrument has large $t$-statistics and the $F$-statistic on the joint significance of the instruments is 1,560. Coefficients change little with inclusion of controls. The reduced-form estimates confirm, in the vicinity of the July 1 cutoff, a statistically 
significant decline of around one percentage point in the retention probability (see Columns 4 to 6 ).

Table 4, Panel A reports TSLS estimates that exploit enrollment age variation at all four cutoffs to estimate causal effects. In Column 1, an OLS estimate with student controls suggests that increasing enrollment age has a negative but small effect on the probability of being retained in the first grade. Descriptive statistics implied that such an estimate would be biased because disadvantaged students-more likely to be retained-voluntarily delay enrollment. In fact, the estimates from TSLS specifications are over three times the magnitude of OLS estimates and stable across specifications. They suggest that a one-year delay in enrollment lowers the probability of repeating first grade by 2.1 percentage points. In the over-identified regression, Hansen $J$ tests produce $p$-values above 0.4 , providing no evidence against the instruments' validity. Durbin-Wu-Hausman tests reject the null hypothesis that enrollment age is exogenous and justify using TSLS (though having a million observations makes a large test statistic more likely).

Panels B to E report four exactly identified models that use sharp variation around each cutoff as a single excluded instrument. The estimates that rely on variation around April 1 and June 1 have negative signs, with larger magnitude than previous results and imprecise estimates. The estimates relying on variation around May 1 have positive signs and larger standard errors. Given the strength of the July 1 instrument, estimates in Panel E are very similar to estimates in Panel A.

\section{B. Evidence of Birth Timing}

In Chile, as in many countries, scheduled births cause the frequency of birthdate distributions to decline on weekends and holidays (Dickert-Conlin and Chandra 1999). The top panel of Figure 2 illustrates the weekend dip among sample children born in 1996. This dip is not evident among a pooled sample of all birth years (bottom panel), though births noticeably decline on three national holidays, two of which are close to enrollment cutoffs. In the sample data, mothers of Sunday births have 0.18 fewer years of schooling, relative to Mondays, and mothers of holiday births have 0.07 fewer years, relative to other days (McEwan and Shapiro 2006).

A first, less pressing concern is that enrollment cutoffs coincidentally fall near weekends and holidays, as Figure 2 shows happened in 1996. Even in the absence of strategic birth timing, such coincidence could introduce correlation between enrollment age and mother's schooling (or unobservables). Despite these concerns, controlling for day-of-week and holiday indicators in regressions barely changes estimates (Tables 3 and 4).

A second, more pressing concern is that parents precisely time births around enrollment cutoffs. The birth histogram in the full sample (Figure 2, bottom panel) reveals no obvious changes in birth date density around the enrollment cutoffs, though the rough distribution of discrete birthdates obscures comparisons. Parents are unlikely to purposefully schedule births after cutoffs, since they can voluntarily delay enrollment. More likely, parents would schedule births before cutoffs, thus avoiding a strictly enforced minimum age. Scheduled births might occur in families of relatively higher income and schooling, who have better access to medical 

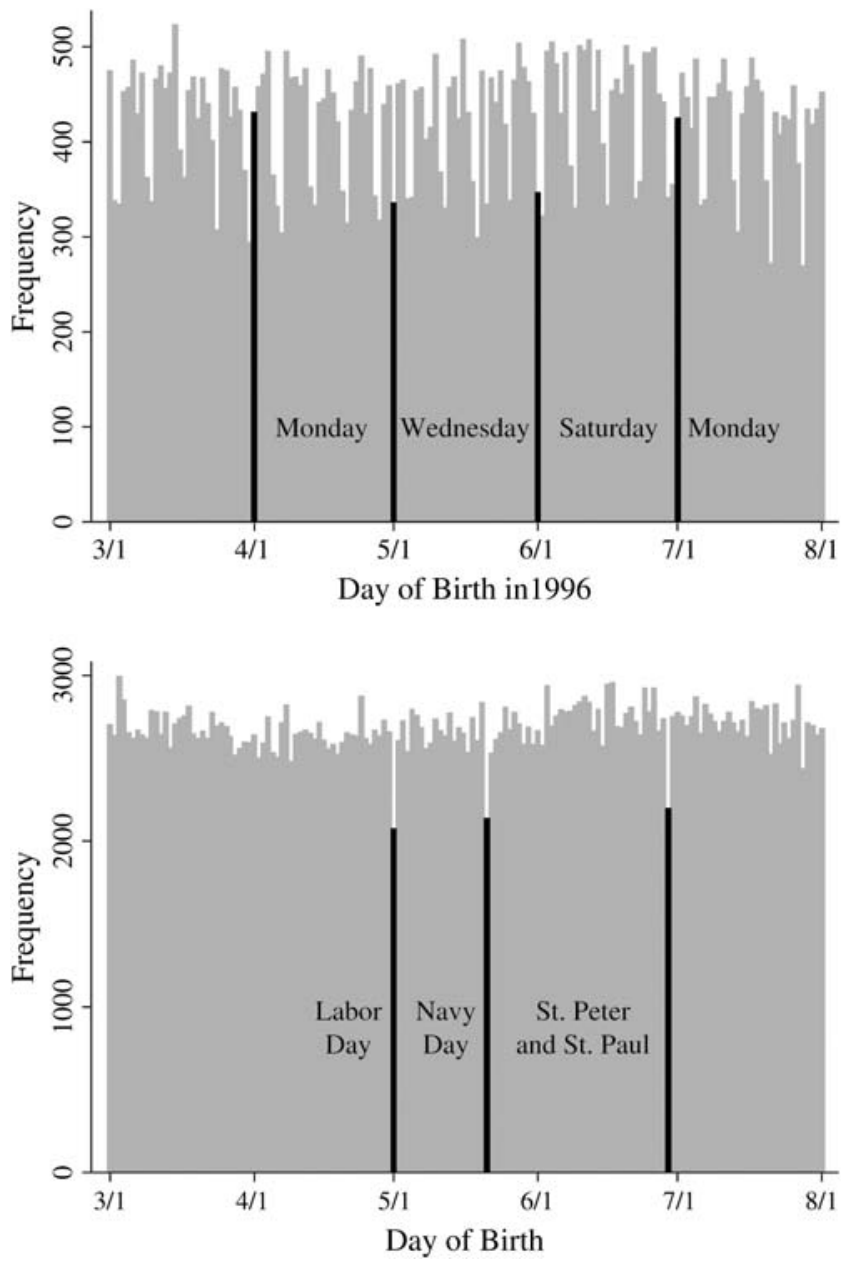

\section{Figure 2}

Day of Birth Histograms, in 1996 and Pooled across Birth Years

Source: JUNAEB sample.

Note: The top panel includes children born in 1996, and the bottom panel includes all children. The three labeled bars indicate holidays on May 1 (Labor Day), May 21 (Navy Day), and June 29 (St. Peter and St. Paul).

services and knowledge of school policies. Birth timing of this kind would bias effects on grade retention toward zero, presuming that families born before cutoffs have spuriously low retention rates. Our estimates suggest large impacts despite this potential bias. 


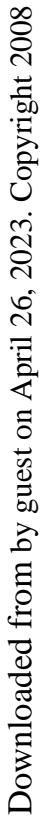

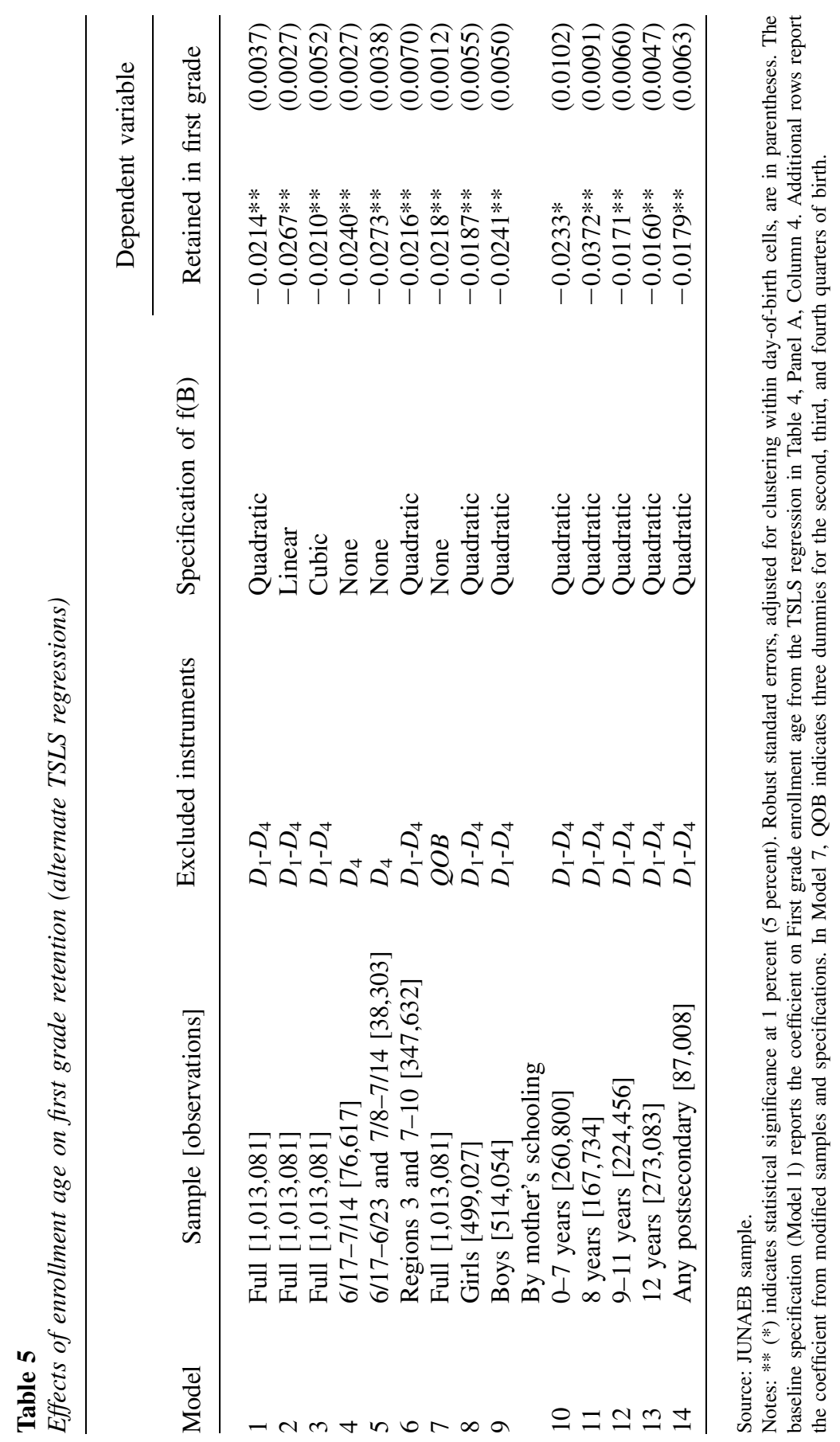



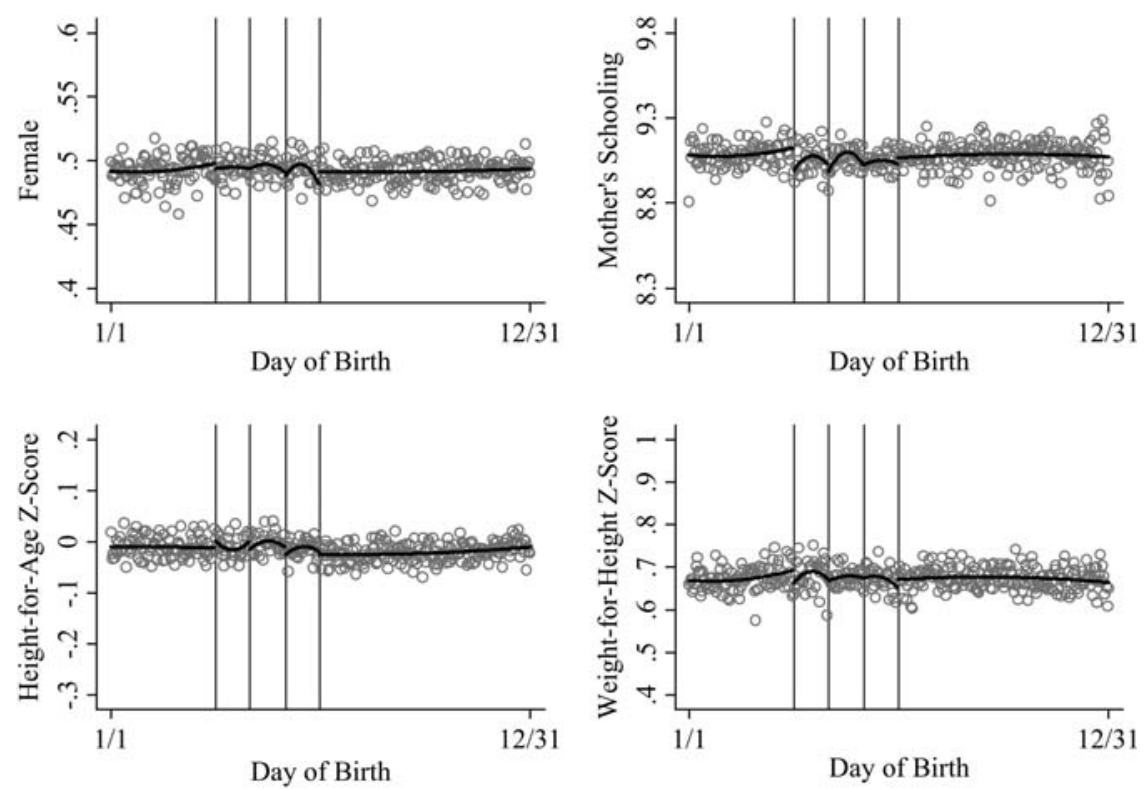

\section{Figure 3}

Testing Smoothness of Baseline Variables across Enrollment Cutoffs

Source: JUNAEB sample.

Note: The dots are mean values of the $y$-axis variable within each day of birth. The solid lines are fitted values from a piecewise quadratic of day of birth (see text for details). The y-axis of continuous variables is scaled to about half a standard deviation. The four vertical lines in each panel are placed at April 1, May 1, June 1, and July 1.

As an additional check, we assess whether students' characteristics vary sharply near enrollment cutoffs. ${ }^{22}$ Figure 3 plots the mean values of student characteristics within day-of-birth cells, revealing no large breaks near cutoffs and even little seasonality. To confirm these findings, we estimate four variants of Equation 2, using student attributes as dependent variables. Of 16 coefficients on the four $D_{j}$, only two are statistically significant ( $D_{1}$ for mother's schooling, and $D_{4}$ for female), though they have small magnitude. ${ }^{23}$

22. We expect student height and weight to differ sharply across early and late-entering students, given a difference in age when the measurement it taken at the beginning of first grade (the results are available from the authors). However, we do not anticipate sharp differences in age-adjusted $Z$-scores, unless parents on either side of cutoffs respond to assigned enrollment dates by altering investments in nutrition.

23. McEwan and Shapiro (2006) report the complete estimates. Results are also insensitive to including day-of-week and holiday indicators. 


\section{Robustness and Heterogeneous Effects}

The first row of Table 5 (Model 1) reports the original TSLS estimate of $\beta_{l}$ from Table 4, Panel A, Column 4. Subsequent rows report estimates from varying samples and specifications. Models 2 and 3 vary the specification of $f(B)$ in the first- and second-stage regressions. A piecewise linear specification yields a more negative point estimate of -0.027 , while a piecewise cubic produces an estimate very similar to the baseline. Model 4 limits the sample to children born in two-week intervals on either side of the July 1 cutoff, diminishing reliance on arbitrary functional form assumptions and data far from the cutoff (Chay, McEwan, and Urquiola 2005). The point estimate of -0.024 is very similar. Model 5 adds an additional sample restriction to Model 4, dropping students in one-week intervals on either side, since precise timing is most likely to occur in these days. The point estimate becomes only slightly more negative. Model 6 reestimates the baseline specification using five of Chile's 13 regions with less sample selection, ${ }^{24}$ yielding a similar point estimate to the baseline.

Model 7 assesses whether simpler, quarter-of-birth instruments and no controls for smooth functions of birth dates in TSLS regressions, in the spirit of Angrist and Krueger (1991), can obtain the same results. The usual concern is that seasonality in conception creates correlations between quarter of birth and unexplained variation in outcomes (Bound, Jaeger, Baker 1995; Bound and Jaeger 2000). Figure 3 was not consistent with this concern, given the flat relationship between birth date and common correlates of outcomes. In fact, the point estimate of the simpler model is nearly identical to the baseline, suggesting that in Chilean data, coarser birth date measures can be a useful source of identification.

Finally, we estimate the baseline specification in subsamples to assess how effects on retention vary across different children. Reductions in first grade retention are slightly larger for boys (Models 8-9), and for children whose mothers have relatively less schooling (models 10-14). However, boys and children of less-educated mothers also have higher baseline retention rates. For example, in the lowest and highest groups of mother's schooling defined in Table 5, the mean first grade retention is 0.053 and 0.001 , respectively. ${ }^{25}$

\section{Effects on Test Scores}

\section{A. Results}

In the fourth grade SIMCE sample, Figure 4 (top-left) shows that first grade enrollment age increases sharply at cutoffs, as in Figure 1, but with slightly more noise. The estimated breaks in first-stage regressions are similar those in the full sample- -0.48 years on July 1 , and 0.07 to 0.13 years at earlier cutoffs. ${ }^{26}$ The lower

24. The subsample includes 84 (87) percent of schools (students) (McEwan and Shapiro 2006).

25. In subsamples of boys and girls, the first grade retention rates are 0.030 and 0.025 , respectively. Elder and Lubotsky (2006) find similar patterns across socioeconomic quartiles in U.S. data.

26. The F-statistic on joint significance of the instruments is 134 in the specification like that of Table 3 (Column 1) and 116 with a full set of controls (Column 3). Full first-stage results for test score regressions appear in McEwan and Shapiro (2006). 

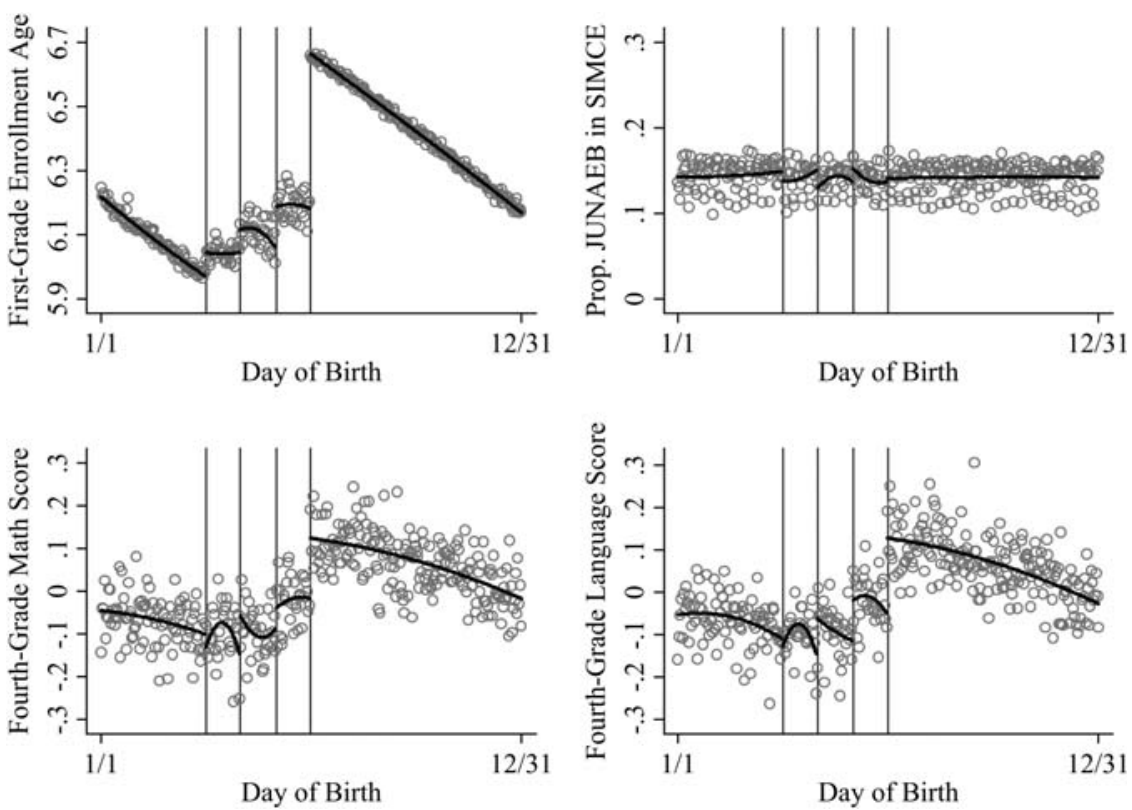

\section{Figure 4}

Day of Birth, First grade Enrollment Age, and Fourth grade Test Scores Source: SIMCE sample.

Note: The dots are mean values of the $y$-axis variable within each day of birth. The solid lines are fitted values from a piecewise quadratic of day of birth (see text for details). The four vertical lines in each panel are placed at April 1, May 1, June 1, and July 1.

panels of Figure 4 illustrate the reduced-form discontinuity analysis for fourth grade math and language test scores. The unsmoothed means and fitted values suggest changes of 0.15 to 0.2 standard deviations in test scores at the July 1 cutoff. Table 6 reports TSLS estimates for fourth grade math and language test scores (Panel A, Model 1) that rely on sharp variation in enrollment age at all cutoffs. The reported estimates include a full set of controls (see table note). They suggest that delaying enrollment by one year increases fourth grade test scores by a statistically-significant 0.29 standard deviations in math and 0.38 standard deviations in language. Birth histograms and comparisons of student variables across cutoffs show no evidence of birth timing (McEwan and Shapiro 2006).

In the TIMSS sample, the first-stage estimates show an increased age of 0.4 years for children born on July 1, with a $t$-statistic of 3.9 in the fully specified model. Estimates of breaks at earlier cutoffs have statistically insignificant coefficients-despite magnitudes consistent with other samples-and $F$-statistics on joint significance do not exceed 13 (McEwan and Shapiro 2006). In TSLS estimates for the eighth grade data, we use only a single excluded instrument $\left(D_{4}\right)$ in an exactly identified version 


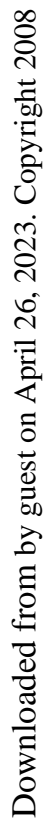

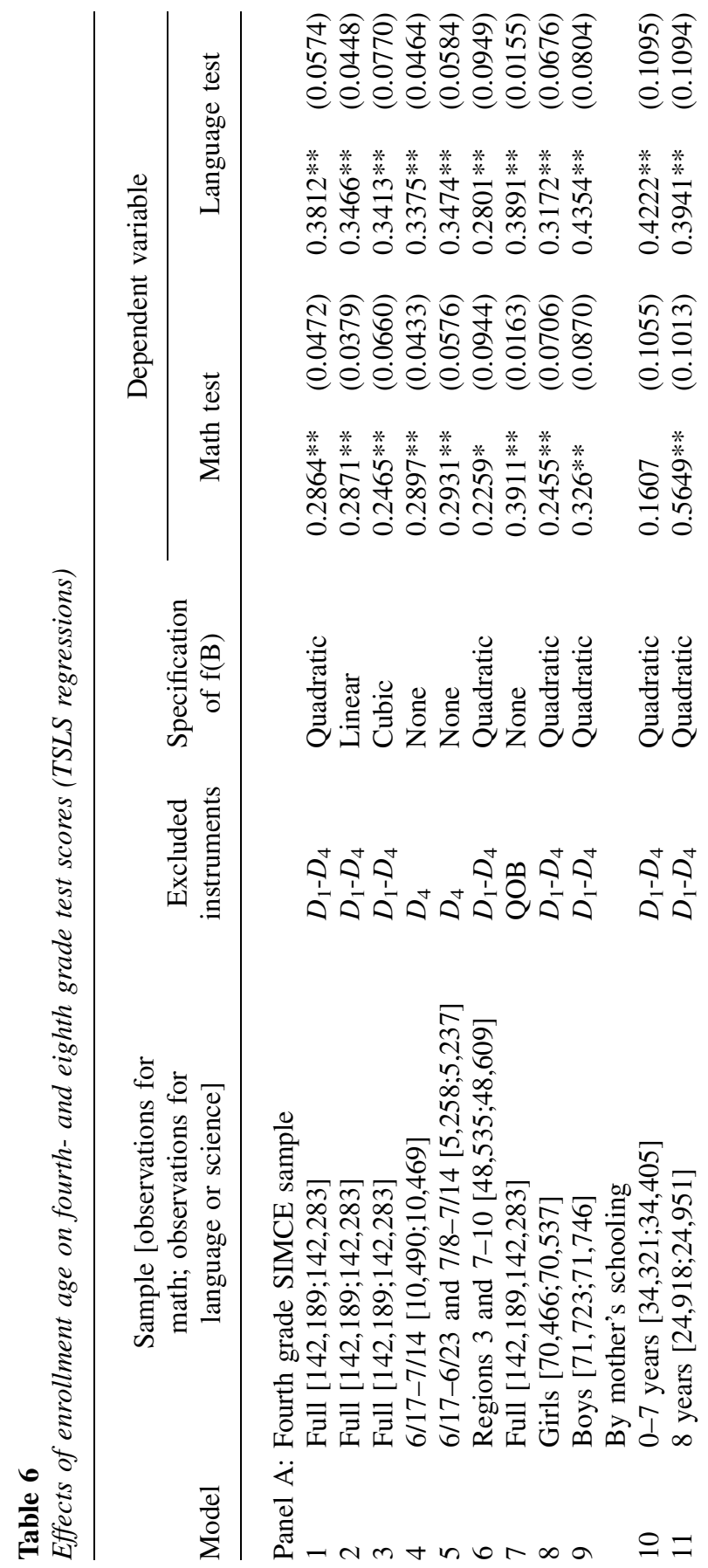




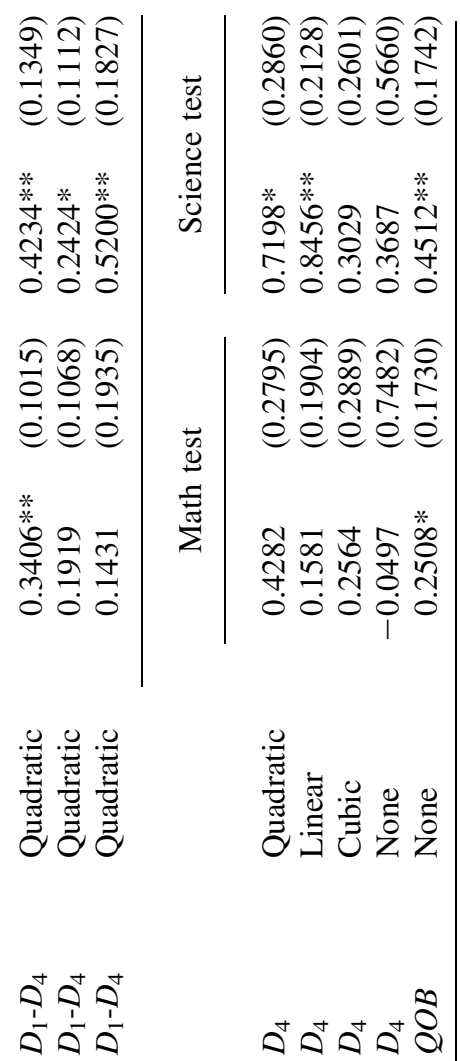

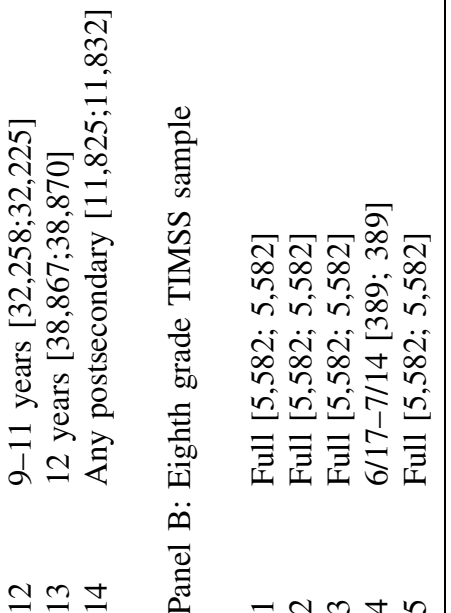

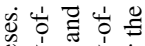

死 oî 死

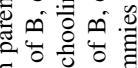

$\exists .00$

$\Rightarrow$ 㱐

ต่

过

E उे

讨

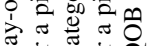

需苛

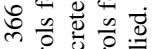

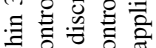

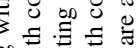

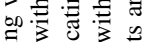

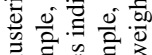

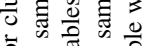

떰

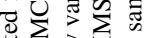

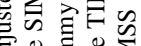

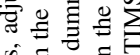

si $\Xi \Xi$

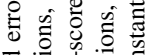

马्ये

可

通

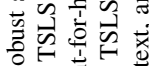

$\approx \approx$

जิ

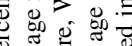

¿

政

웡

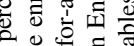

용

的部

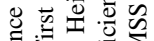

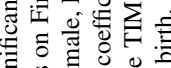

.

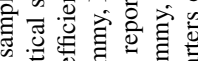

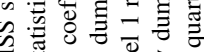

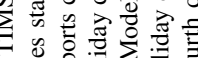

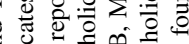

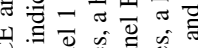

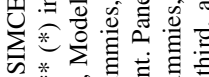

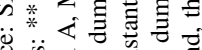

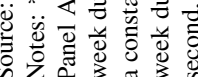


of Equations 4 and 5. In Table 6 (Panel B, Model 1), the full TSLS estimates show that a one-year increase in enrollment age increases eighth grade test scores by 0.43 standard deviations in math and 0.72 standard deviations in science. The former coefficient is statistically insignificant at 5 percent, though its $t$-statistic exceeds 1.5.

Interpretation of test score effects requires several caveats. First, student drop-outs in upper grades could introduce sample selection bias if they occur near enrollment cutoffs. However, enrollment rates are above 98 percent in age groups between seven and 13 (McEwan, Forthcoming). The top-right panel of Figure 4 and other regression estimates (available from the authors) confirm that the proportion of first graders matched to fourth grade records does not vary sharply around enrollment cutoff dates.

Second, both test score samples include retained students. Grade retention and the concomitant reshuffling of first grade cohorts across upper-primary grades could undermine the identification strategy. Consider the sample of fourth graders in 2002. Over 90 percent did not repeat a grade, having entered first grade in 1999 (Table 1). Eight percent were retained, having begun first grade in 1998. They "replace" a portion of retained 1999 entrants who will not reach fourth grade until at least 2003.

Our evidence suggests that repeaters are disproportionately students born to the left of enrollment cutoffs, perhaps creating unobserved differences between students on either side of cutoffs. These differences could undermine identifying Assumption 6. However, if the two compositional effects cancel out close to enrollment cutoffs, this effect will not bias estimates. In practical terms, the 2002 sample would add repeaters from the 1998 cohort of first graders, "replacing" repeaters from the 1999 cohort that have yet to reach the fourth grade. The two groups are perhaps similar in size and similar in unobserved characteristics associated with grade repetition, partly confirmed by the absence of differences in observed characteristics across breaks.

Third, the grade-specific samples are each dominated by two birth year cohorts (1992 and 1993, in the case of fourth graders). Students to the right of the July 1 cutoff, who delay enrollment, are drawn from the older cohort. To identify enrollment age effects at discontinuities in such sample, we do not include a birth year dummy. The absence of sharp differences in observed student characteristics, and the replication of test score effects across two samples, provides a measure of confidence that our estimates are not explained by coincidental effects across birth year cohorts.

\section{B. Robustness and Heterogeneity}

Table 6 repeats the robustness checks performed in the JUNAEB sample. The SIMCE results (Panel A) are insensitive to changing the specification of $f(B)$, or to using narrow bands of data around the July 1 cutoff. The language results are insensitive to using quarter-of-birth instruments, though math results are not. The coefficients in regional subsamples decline somewhat, but are still around one-quarter of a standard deviation. Given the small sample, the TIMSS results are more sensitive, but the coefficients are still uniformly positive and similar in magnitude to the fourth grade estimates. 
In the fourth grade sample, a one-year increase in enrollment age improves boys' test scores by about one-third more than girls. Some evidence indicates that math effects are larger among children of less-educated mothers, although the pattern of effects is not monotone, and there is no such pattern for language effects.

\section{Discussion}

\section{A. Homogeneous Results}

Enrollment age effects, though causal, operate through three pathways. Students who delay enrollment will be older when schools evaluate them. In support of this age-attest effect, Elder and Lubotsky (2006) find large effects of "enrollment age" on test scores in the Fall of kindergarten, before schools could plausibly contribute to learning (also see Datar 2006). Such effects might fade over time, since a year of maturation represents more learning among young children than among adolescents (Bedard and Dhuey 2006; Elder and Lubotsky 2006).

Second, delayed enrollment increases a student's absolute age of enrollment. Older students acquire cognitive, social, linguistic, or physical abilities-often termed "school readiness" - that may allow them to learn more in school than younger children do (see Stipek 2002).

Third, delayed enrollment increases a student's age of enrollment relative to her classmates. In Chile, a plausible relative age effect operates through primary school admissions, since some publicly-funded private schools select students from admissions queues (Gauri 1998). If maturation gives older students an advantage when they apply, and maturation affects factors considered in school admissions, then private schools with a queue may select disproportionately older children. School personnel also could introduce differences in the educational inputs that relatively older and younger children receive in primary grades. Grouping students by ability ("tracking") may place older children in higher ability groups (Bedard and Dhuey 2006), but also could disproportionately allocate compensatory programs like remedial tutoring toward lower-achieving, relatively young students (Chay, McEwan, and Urquiola 2005).

Our results cohere more with enrollment age effects than with age-at-test effects. Elder and Lubotsky (2006) find declining enrollment age effects in upper grades, interpreted as evidence of dominant age-at-test effects. Bedard and Dhuey (2006) find more persistent effects that decline slightly by eighth grade, and argue that age-at-test effects cannot fully explain results. Our findings on test scores show persistent or increasing effects, consistent with either absolute or relative enrollment age effects. Because of prevalent school choice in Chile (McEwan and Carnoy 2000), we suspect that that relative age effects play some role. Correspondingly, Chilean results may have limited implications for countries with less school choice.

\section{B. Heterogeneous Results}

A one-year delay produces larger decreases in retention probabilities among students with less-educated mothers, though heterogeneity in test score effects is inconsistent. One explanation for the pattern of retention effects focuses on retention as a binary 
indicator of a student's unobserved achievement at the end of first grade. Suppose we have populations of high- and low- achieving students identified by superscripts $H$ and $L$, respectively. Each student has unobserved achievement $a_{i}$, with $a_{i}^{H} \sim N$ $\left(\mu_{H}, \sigma^{2}\right), a_{i}^{L} \sim N\left(\mu_{L}, \sigma^{2}\right)$, and $\mu_{L}<\mu_{H}$. Retention $r_{i}$ indicates that a student failed to meet a low achievement threshold $\bar{a}: r_{i}=1\left\{a_{i}<\bar{a}\right\}$ where $1\{\cdot\}$ is the indicator function and $\bar{a}<\min \left\{\mu_{L}, \mu_{H}\right\}$. Suppose that delaying enrollment improves the achievement of all students by the scalar $\phi$. If $F^{p}(\cdot)$ denotes the cumulative distribution function and $f^{p}(\cdot)$ denotes the density function both for population $p$, then the change in retention rate due to delayed enrollment for population $p$ is

$$
\int_{\bar{a}-\phi}^{\bar{a}} f^{p}(a) d a=F^{p}(\bar{a})-F^{p}(\bar{a}-\phi)
$$

A normal density function has positive slope for values below its mean. Since $\mu_{L}<\mu_{H}$, since both distributions are normal with the same variance, and since $\bar{a}<\min \left\{\mu_{L}, \mu_{H}\right\}$, we obtain

$$
F^{L}(\bar{a})-F^{L}(\bar{a}-\phi)>F^{H}(\bar{a})-F^{H}(\bar{a}-\phi)
$$

The inequality shows that delayed enrollment will affect the retention of low-achieving students-perhaps those with less-educated mothers-more than that of highachieving students, even if effects on unobserved first grade achievement are homogeneous.

Among boys, delaying enrollment produces consistently larger decreases in retention and larger increases in test scores. One explanation is that similarly aged boys and girls possess different levels of school readiness. In particular, similarly aged boys might be less mature or "ready" for schooling. Some psychologists believe that increased readiness - the result of delayed enrollment and maturation-only improves children's later schooling outcomes until a threshold level of readiness is reached (Stipek 2002). If more girls already exceed this threshold at a given age than boys do, then the marginal effect of an additional one-year delay would be lower among girls.

\section{Conclusions and Policy Implications}

An exogenous one-year delay in first grade enrollment decreases the probability of first grade retention by about two percentage points, relative to a baseline of 2.8 percent, and increases fourth- and eighth grade test scores by 0.3 or more standard deviations. The persistent effects suggest that absolute or relative enrollment age, rather than age-at-test, explain these results.

Policymakers debate whether to uniformly increase enrollment ages by moving cutoff dates earlier in the year. The general equilibrium effects of such a policy depend on the (uncertain) causal pathways. First, if age-at-test effects dominate, then such a policy would increase early grade test scores without increasing learning, simply because students would be older when tested. The policy could even widen inequality, if advantaged students experience greater test score gains while out of 
school (Elder and Lubotsky 2006; Stipek 2002). Second, if relative age effects dominate, then moving cutoff dates earlier would merely redistribute achievement among students without increasing mean test scores. Third, if absolute age effects dominate, then raising mean enrollment age would increase mean test scores by improving students' readiness for school.

The uncertain benefits of uniformly increasing the mean enrollment age must be weighed against potentially large costs: childcare, shortened work careers, and lower attainment. The relatively low incidence of voluntary enrollment delays, at least in Chile, suggests that the benefits of delays outweigh costs for only a small proportion of families. Among such families, voluntary delays can be viewed as a rational and tacit investment in the human capital of disadvantaged children. ${ }^{27}$ Much evidence from developing countries suggests, for example, that families voluntarily delay enrollment of malnourished and stunted children (Alderman, Hoddinott, and Kinsey 2006; Glewwe and Jacoby 1995; Glewwe, Jacoby, and King 1999; McEwan 2006; Partnership for Child Development 1999). Instead of permitting tacit investments through voluntary delays-or mandating delays for all children-policymakers might instead consider direct, targeted investments in children's school readiness, such as early childhood nutrition (Rawlings and Rubio 2005) and preschool (Berlinski, Galiani, and Gertler 2006; Gormley and Gayer 2005).

\section{References}

Alderman, Harold, John Hoddinott, and Bill H. Kinsey. 2006. "Long term Consequences of Early Childhood Malnutrition." Oxford Economic Papers 58(3):450-74.

Angrist, Joshua D., and Guido W. Imbens. 1995. "Two-Stage Least Squares Estimation of Average Causal Effects in Models with Variable Treatment Intensity." Journal of the American Statistical Association 90(430):431-42.

Angrist, Joshua D., and Alan B. Krueger. 1991. "Does Compulsory School Attendance Affect Schooling and Earnings?" Quarterly Journal of Economics 106(4):979-1014.

Bedard, Kelly, and Elizabeth Dhuey. 2006. "The Persistence of Early Childhood Maturity: International Evidence of Long-Run Age Effects." Quarterly Journal of Economics 121(4):1437-72.

Belizán, José M., Fernando Althabe, Fernando C. Barros, and Sophie Alexander. 1999. "Rates and Implications of Caesarean Sections in Latin America: Ecological Study." BMJ 319:1397-1400.

Berlinski, Samuel, and Sebastian Galiani. 2007. "The Effect of a Large Expansion of PrePrimary School Facilities on Preschool Attendance and Maternal Employment." Labour Economics. Forthcoming.

Berlinski, Samuel, Sebastian Galiani, and Paul Gertler. 2006. “The Effect of Pre-Primary Education on Primary School Performance." Working Paper W06/04. London: The Institute for Fiscal Studies.

27. Glewwe and Jacoby (1995) formalize this intuition by adding to a dynamic human capital model the assumption that some children are less ready for school at a specified enrollment age, and that voluntary delays increase readiness. They further assume that readiness at enrollment increases subsequent earnings, providing the necessary scope for some families to delay enrollment voluntarily, despite the associated costs. Delayed enrollment in poor settings also could reflect credit constraints, if families are unable to finance the direct or indirect costs of primary school (Bommier and Lambert 2000; Glewwe and Jacoby 1995). 
Bommier, Antoine, and Sylvie Lambert. 2000. "Education Demand and Age at School Enrollment in Tanzania." Journal of Human Resources 35(1):177-203.

Bound, John, and David A. Jaeger. 2000. "Do Compulsory Attendance Laws Alone Explain the Association Between Earnings and Quarter of Birth?" In Research in Labor Economics: Worker Well-Being, ed. Solomon W. Polacheck, 83-108. New York: JAI.

Bound, John, David A. Jaeger, and Regina M. Baker. 1995. "Problems With Instrumental Variables Estimation When the Correlation Between the Instruments and the Endogenous Explanatory Variable Is Weak." Journal of the American Statistical Association 90(430):443-50.

Cascio, Elizabeth. 2006. "Public Preschool and Maternal Labor Supply: Evidence from the Introduction of Kindergartens into American Public Schools.” Working Paper 12179. Cambridge: National Bureau of Economic Research.

Cascio, Elizabeth U., and Ethan G. Lewis. 2006. "Schooling and the AFQT: Evidence from School Entry Laws." Journal of Human Resources 41(2):294-318.

Chay, Kenneth Y., Patrick J. McEwan, and Miguel Urquiola. 2005. "The Central Role of Noise in Evaluating Interventions That Use Test Scores to Rank Schools." American Economic Review 95(4):1237-58.

Datar, Ashlesha. 2006. "Does Delaying Kindergarten Entrance Give Children a Head Start?" Economics of Education Review 25(1):43-62.

Dickert-Conlin, Stacy, and Amitabh Chandra. 1999. "Taxes and the Timing of Births." Journal of Political Economy 107(1):161-77.

Elder, Todd E., and Darren H. Lubotsky. 2006. "Kindergarten Entrance Age and Children's Achievement: Impacts of State Policies, Family Background, and Peers." University of Illinois at Urbana-Champaign. Unpublished.

Fredriksson, Peter, and Björn Öckert. 2005. "Is Early Learning Really More Productive? The Effect of School Starting Age on School and Labor Market Performance?" Uppsala University. Unpublished.

Gauri, Varun. 1998. School Choice in Chile. Pittsburgh: University of Pittsburgh Press. Gelbach, Jonah B. 2002. "Public Schooling for Young Children and Maternal Labor Supply." American Economic Review 92(1):307-22.

Glewwe, Paul, and Hanan G. Jacoby. 1995. "An Economic Analysis of Delayed Primary School Enrollment in a Low Income Country: The Role of Early Childhood Nutrition." Review of Economics and Statistics 77(1):156-69.

Glewwe, Paul, Hanan G. Jacoby, and Elizabeth M. King. 2001. "Early Childhood Nutrition and Academic Achievement: A Longitudinal Analysis." Journal of Public Economics 81(3):345-68.

Gormley, William T., and Ted Gayer. 2005. "Promoting School Readiness in Oklahoma: An Evaluation of Tulsa's PreK Program." Journal of Human Resources 40(3):533-58.

Hsieh, Chang-Tai, and Miguel Urquiola. 2006. "The Effects of Generalized School Choice on Achievement and Stratification: Evidence from Chile's Voucher System." Journal of Public Economics 90(8-9):1477-1503.

Lee, David S. Forthcoming. "Randomized Experiments from Non-Random Selection in U.S. House Elections. Journal of Econometrics.

Lee, David S., and David Card. Forthcoming. "Regression Discontinuity Inference with Specification Error." Journal of Econometrics.

Lemieux, Thomas, and Kevin Milligan. 2005. "Incentive Effects of Social Assistance: A Regression Discontinuity Approach.” University of British Columbia. Unpublished.

McCrary, Justin. Forthcoming. "Manipulation of the Running Variable in the Regression Discontinuity Design: A Density Test." Journal of Econometrics. 
McCrary, Justin, and Heather Royer. 2006. "The Effect of Maternal Education on Fertility and Infant Health: Evidence from School Entry Laws Using Exact Date of Birth." University of Michigan. Unpublished.

McEwan, Patrick J. 2006. "Delayed Primary School Enrollment in Eight Latin American Countries." Wellesley College. Unpublished.

. Forthcoming. "Can Schools Reduce the Indigenous Test Score Gap? Evidence from Chile." Journal of Development Studies.

McEwan, Patrick J., and Martin Carnoy. 2000. "The Effectiveness and Efficiency of Private Schools in Chile's Voucher System." Educational Evaluation and Policy Analysis 22(3):213-39.

McEwan, Patrick J., and Joseph S. Shapiro. 2006. "The Consequences of Delayed Primary School Enrollment in a Developing Country." Wellesley College and LSE. Unpublished.

Murray, Susan F. 2000. "Relation between Private Health Insurance and High Rates of Caesarean Section in Chile: Qualitative and Quantitative Study." BMJ 321:1501-1505.

Partnership for Child Development. 1999. "Short Stature and the Age of Enrolment in Primary School: Studies in Two African Countries." Social Science and Medicine 48(5):675-82.

Rawlings, Laura B., and Gloria M. Rubio. 2005. "Evaluating the Impact of Conditional Cash Transfers." World Bank Research Observer 20(1):29-55.

República de Chile. 1992. "Determina Fecha en Que Reconoce Cumplimento de Edad de Ingreso a la Educación Parvularia Segundo Nivel de Transición y Educación Básica." Santiago: República de Chile, Ministerio de Educación.

Stipek, Deborah. 2002. "At What Age Should Children Enter Kindergarten? A Question for Policy Makers and Parents." Social Policy Report 16(2):3-17.

UNESCO. 2007. "Length and Starting Age of Compulsory Education for Schools Years 1998/1999 to 2004/2005." UNESCO Institute for Statistics.

Urquiola, Miguel, and Valentina Calderón. 2006. "Apples and Oranges: Educational Enrollment and Attainment across Countries in Latin America and the Caribbean." International Journal of Educational Development 26(6):572-90.

van der Klaauw, Wilbert. 2002. "Estimating the Effect of Financial Aid Offers on College Enrollment: A Regression-Discontinuity Approach." International Economic Review 43(4):1249-86.

Yamamoto, Kentaro, and Edward Kulik. 2000. "Scaling Methodology and Procedures for the TIMSS Mathematics and Science Scales.” In TIMSS 1999 Technical Report, ed. Michael O. Martin, Kelvin D. Gregory, and Steven E. Stemler, 259-77. Boston: International Study Center, Boston College. 